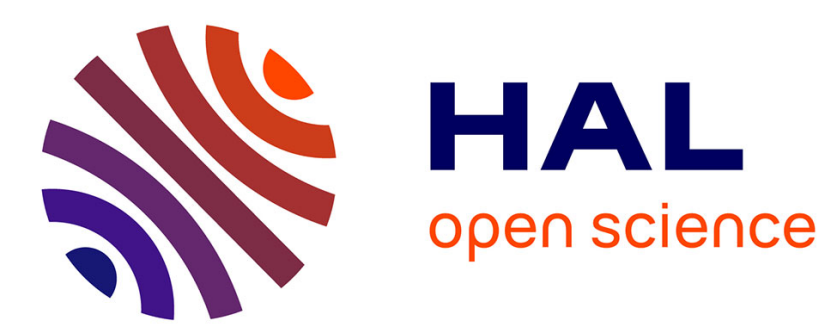

\title{
Two- and three-dimensional shape fabric analysis by the intercept method in grey levels
}

Patrick Launeau, C.J. Archanjo, David Picard, Laurent Arbaret, Pierre-Yves Robin

\section{- To cite this version:}

Patrick Launeau, C.J. Archanjo, David Picard, Laurent Arbaret, Pierre-Yves Robin. Two- and threedimensional shape fabric analysis by the intercept method in grey levels. Tectonophysics, 2010, 492 (1-4), pp.230-239. 10.1016/j.tecto.2010.06.005 . insu-00509163

\section{HAL Id: insu-00509163 \\ https://hal-insu.archives-ouvertes.fr/insu-00509163}

Submitted on 10 Feb 2011

HAL is a multi-disciplinary open access archive for the deposit and dissemination of scientific research documents, whether they are published or not. The documents may come from teaching and research institutions in France or abroad, or from public or private research centers.
L'archive ouverte pluridisciplinaire HAL, est destinée au dépôt et à la diffusion de documents scientifiques de niveau recherche, publiés ou non, émanant des établissements d'enseignement et de recherche français ou étrangers, des laboratoires publics ou privés. 


\title{
Two- and three-dimensional shape fabric analysis by the intercept method in grey levels
}

\author{
Patrick Launeau $\stackrel{a}{ }$, Carlos J. Archanjo ${ }^{\underline{b}}$, David Picard ${ }^{\underline{c}}$, Laurent Arbaret ${ }^{\underline{c}}$ and Pierre- $^{-}$ \\ Yves Robin ${ }^{\text {d }}$
}

${ }^{a}$ Laboratoire de Planétologie et Géodynamique de Nantes, UMR 6112, CNRS/Université de Nantes, 2 rue de la Houssinière, 44322 Nantes, France

${ }^{\mathrm{b}}$ Instituto de Geociências, USP, Rua do Lago 562, 05508-080 São Paulo, SP, Brazil

${ }^{\mathrm{c}}$ Institut des Sciences de la Terre d'Orléans, UMR 6113, CNRS/Université d'Orléans 1A rue de la Férollerie, 45071 Orléans, France

${ }^{\mathrm{d}}$ University of Toronto, Department of Geology, 22 Russell St., Toronto, Ontario, Canada M5S 3B1

\begin{abstract}
The count intercept is a robust method for the numerical analysis of fabrics Launeau and Robin (1996). It counts the number of intersections between a set of parallel scan lines and a mineral phase, which must be identified on a digital image. However, the method is only sensitive to boundaries and therefore supposes the user has some knowledge about their significance. The aim of this paper is to show that a proper grey level detection of boundaries along scan lines is sufficient to calculate the two-dimensional anisotropy of grain or crystal distributions without any particular image processing. Populations of grains and crystals usually display elliptical anisotropies in rocks. When confirmed by the intercept analysis, a combination of a minimum of 3 mean length intercept roses, taken on 3 more or less perpendicular sections, allows the calculation of 3-dimensional ellipsoids and the determination of their standard deviation with direction and intensity in 3 dimensions as well. The feasibility of this quick method is attested by numerous examples on theoretical objects deformed by active and passive deformation, on BSE images of synthetic magma flow, on drawing or direct analysis of thin section pictures of sandstones and on digital images of granites directly taken and measured in the field.
\end{abstract}

Keywords: Shape preferred orientation; Fabric; Structural geology; Intercepts; Image analysis

\section{Introduction}

The intercept method is based on counting the number of intercepted segments of a set of objects on the image by a set of parallel scan lines along a number of directions. In practice, the intercept number is the count of boundaries found by moving out of an object along a scan line (Fig. 1). Polar plots, or rose diagrams, of the number of intercepts in each direction were defined in material science by (Saltykov, 1958) and (Underwood, 1970). The method began to be used in geology by (Panozzo, 1983), (Panozzo, 1984) and (Panozzo, 1987), who was also 
aware of the difficulty of counting intercepts on digital images (Panozzo Heilbronner, 1988. The application to digital images was presented by Launeau et al. (1990) and fully formalized by Launeau and Robin (1996) with the addition of a Fourier analysis of the intercept count and the definition of the rose of traverses or the rose of mean intercept length obtained by dividing the area of all objects of interest by the number of intercepts in each direction.

It is often difficult to identify all the boundaries when objects are crystals or grains interconnected to each other in images. Some boundaries are missing, hence the crystal or grain sizes are biased. However, since the intercept method is only sensitive to boundaries, it remains applicable and can still be used to analyze the anisotropy of aggregated objects when a significant percentage of crystal or grain boundaries remain visible (Launeau et al., 1990).

In the procedure presented by Launeau and Robin (1996), it was necessary to threshold or classify the image to distinguish a phase from its background. In this new version, based on the detection of intercepts in grey levels, the time-consuming imaging pre-processing can be drastically reduced. It does not use classical edge detection, which produced too many artifacts, as inferred from Panozzo Heilbronner (1988), but instead combines a long low-pass filter along scan lines of analysis with a narrow high pass edge detector. This was used by (Lebichot et al., 2005) and (Pirard et al., 2007) for comparison with another grey level detection of intercepts designed for material science projects, where boundaries appear dark between light grey crystals. The present work was optimized for common pictures of rocks, as shown in the following examples.

Alternative methods using grey level images to quantify anisotropy include autocorrelation techniques from Panozzo Heilbronner (1992) or wavelet techniques from Gaillot et al. (1999). Both methods are sensitive to spatial distributions, which are useful to characterize crystal or grain alignments. In contrast, the intercept method is insensitive to crystal alignment and therefore not recommended for such studies. However, it can sample images at high angular resolution to yield many parameters, such as the rose of boundary directions, which can be extracted from the Fourier analysis of their rose diagrams (Launeau and Robin, 1996). Many applications are available from (Diot et al., 2003) and (Romeo et al., 2007). The present grey level version was used by Archanjo et al. (2009). The aim of this presentation is to focus on the limit of the validity of the technique to avoid misuse and misunderstanding of the results.

In structural geology, geologists are often interested in shape preferred orientation (SPO). It can be the SPO of rigid bodies embedded in a viscous matrix indicating a preferential flow direction (also known as active deformation) or the mean shape of a population of objects passively deformed within their surrounding material (also called passive deformation). In both cases, it is a population of a large number of objects. As shown by Launeau (2004) with repeated simulations, individual shapes do not have to be known in great detail. The SPO is mainly sensitive to the degree of preferred orientation, and is therefore usually elliptical when there are enough objects that are not all parallel to each other. When an SPO appears as an ellipse for any section (in 2-D), it is an ellipsoid in volume (in 3-D). This was demonstrated by Robin (2002), who also defined two modes of calculation, one with and one without a scale factor. In the scale factor procedure, the size information is used to build the ellipsoid. However, the lack of boundary detection in some images alters the exact determination of sizes in 2-D. Following the recommendation of Robin (2002), it was therefore necessary to use the ellipsoid construction without a scale factor. A combination of sub-samples, as 
defined by Launeau and Robin (2005), was also used to check the homogeneity of the data for each section and to estimate the 3-D standard deviation of the ellipsoid parameters.

To highlight that no SPO calculation can be fully understood without questioning the mechanical processes involved, a set of synthetic objects, passively and actively deformed, were used to test the intercept method. An application to a famous textbook example enabled the comparison between the application of the intercept method to grey level images and the hand drawing of a quartzite thin section. Application to BSE images of a synthetic magma showed how sub-windows of measurement can be used to check the homogeneity of 2-D SPO and how it can detect significant shear localizations. Finally, a 3-D application showed that foliations and lineations can be quantified in the field, without any prior knowledge of their orientation, with a portable computer and a digital camera. It only requires a minimum of 3 flat and clean random sections, nearly perpendicular to each other, to give the orientation of $x$, $\mathrm{y}$ and $\mathrm{z}$ with the lengths $\mathrm{a}, \mathrm{b}$ and $\mathrm{c}$ of the SPO ellipsoid.

\section{Counting intercepts}

In theory (e.g. [Underwood, 1970], [Serra, 1982] and [Coster and Chermant, 1989]), at a single point $x$, of grid coordinates $(i, j)$, the number of intercepts along a set of points $N_{0}$ is equal to either 1 , when the point is identified as belonging to the phase $X$ analyzed, or 0 when it is not.

\section{$N_{0}(i, f)=1$ if $x$ is on $X$ 0 if $x$ is not on $X$}

and it follows that:

$$
A-a \sum_{i} N_{0}\left(i_{r}\right)-N_{0} a
$$

where $a$ is the surface area credited to each grid point. Typically, $a$ is given by the distance $I$ of successive points on a line, and the distance between lines, $J$, so $a=I \times J$. The area of the window, $A^{w}$, is calculated from the total number of grid points in the window, $N_{0}{ }^{w}$, by

$$
A^{w}=K_{0}^{W} a
$$

and the fraction of $X$ is

$$
f=A f A^{W F}=K_{0} / N_{0}^{W}
$$

Along a test line, say the $j$ th line, the number of intercepts $N_{1}(j)$ is equal to the number of segments of the set of objects intercepted along that line (Underwood 1970, Section 1.3.3). In the automatic analysis of an image, $N_{1}(j)$ is counted on a given test line $j$ by sliding a cursor along that line, i.e. by increasing $i$, and counting all the positions in which, for example, the cursor moves out of $X$, i.e. whenever $N_{0}(i, j)$ changes from 1 to 0 (Fig. 1a). The intercept method is based on adding the number of segments of $X$, on a series of straight parallel lines $j$ having a direction $\alpha$ on the section.

$$
N_{1}(\alpha)=\sum_{i} N(t, \alpha)
$$


By multiplying by the spacing $J$ between the grid lines, one obtains the total diameter intercepted along direction $\alpha$ within the window (Fig. 1),

$D(\alpha)=J N_{1}(\alpha)$

The density of intercepts, $N_{L}(\alpha)$, independent of the size of

the area analyzed, $A^{w}$, and of the spacing, $J$, of the lines (Underwood, 1970, Section 1.3.3) is then obtained from:

$N_{L}(\alpha)=\frac{D(\alpha)}{A^{w}}=\frac{1}{N_{0}^{w}} N_{1}(\alpha)$

Saltykov (1958) was the first to plot $N_{L}(\alpha)$ in polar coordinates (Fig. 1c) and to obtain a rose of intercept densities. One can also calculate and plot the rose of mean intercept distances, $L^{\bar{w}}$ $(\alpha)$, which is simply the reciprocal of $N_{L}(\alpha)$,

$$
\underline{L}^{s}(\alpha)=\frac{1}{N_{L}(\alpha)}=\frac{A^{v}}{\not N_{1}(\alpha)}
$$

When concerned with the objects that make up phase $X$, the mean intercept length,

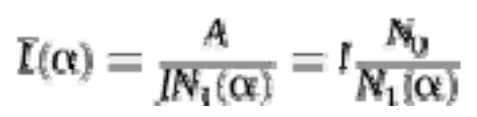

and the corresponding rose, Fig. 1e, are used instead.

The application to digital images is not trivial. It supposes sampling in any $\alpha$ direction with the same $I$ spacing between the points of analysis, despite the fact that pixel spacing varies from 1 in lines and columns to $2^{0.5}$ in diagonals. In practice, a new grid is defined and a point is analyzed at the pixel location that has the closest coordinates (Fig. 2a). This sampling process leads to various artifacts, discussed in Launeau and Robin (1996), such as the multiple detection of intercepts along the scan line tangential to an object boundary, as shown in Fig. 2b. This is avoided by calculating a 10-pixel long weighted density of intercepts, using the following coefficients defined in Launeau and Robin (1996):

A count of intercepts along lines $N_{1}$ is done each time the density line crosses the $50 \%$ density level downward as shown in Fig. 2 b.

Despite this smoothing, a Fourier series analysis is required. Let $F_{M}$ be the Fourier series representation of the rose of intercept counts, $N_{L}(\alpha)$, to its $M$ th harmonic ( $M$ even). Because we impose that the rose of intercept densities is centro-symmetric, and therefore periodic over $\pi$, only even-numbered components differ from 0 . The series can be written as

$F_{M S}(\alpha)=C_{0}+\sum_{m=1}^{M / 2} C_{2 m} \cos 2 m\left(\alpha-\varphi_{2 m}\right)$

Or 
$F_{M}(\alpha)=C_{0}+\sum_{m=1}^{M / 2}\left(A_{2 \omega} \cos 2 m \alpha+B_{2 w} \sin 2 m \alpha\right)$

where $A_{2 m}, B_{2 m}$, and $C_{2 m}$ are the ( $\left.2 m\right)$ th coefficients of the Fourier series, and $\varphi_{2 m}$ is the phase angle of those $(2 m)$ th components. These components are related to each other by:

$\tan 2 m \varphi_{2 m s}=\frac{B_{2 m}}{A_{2 n}}, C_{2 n}^{2}=A_{2 m}^{2}+B_{2 m}^{2}$

Fourier series analysis consists in calculating the components of the series from observations. Numerically, they can be calculated from $K$ actual intercept counts, measured at angular intervals $\delta \alpha(K \delta \alpha=\pi)$. For $N_{L}(\alpha)$,

$\mathrm{C}_{0}=\frac{1}{K_{k}} \sum_{k=0}^{K-1} N_{L}(k \delta \delta)$

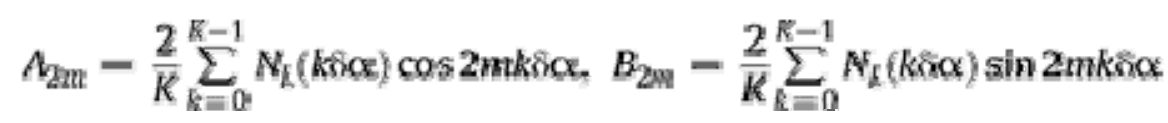

Since the coefficients are calculated from only $K$ independent values of $N_{L}(\alpha)$, we should not expect more than $K$ Fourier coefficients, including $C_{0}$, to be significant. Components should therefore not be calculated beyond $2 M=K-1$. As discussed below, the plot of $C_{2 m}$ versus $m$, also called the power spectrum of the Fourier series, is useful to distinguish a significant signal from a blank noise usually found at high $m$ values. The Fourier series (Eq. (12)) can therefore be truncated below the critical $m$ to remove this blank noise.

\section{Counting intercepts in grey levels}

The grey level method hypothesizes that a mineral phase, a crystal or a grain of it, is a subset of adjacent pixels presenting a short range of grey levels distinct from its neighbors by local sharp drops or ascents of grey levels constituting edges. In such a case, $f$ is equal to $100 \%, A$ confused with $A^{w}$ and thus mean intercept distances are identical to mean intercept lengths. This is typically the case of a monomineral rock. For example, when analyzing the dark grains of biotite surrounded by plagioclase ones, with a lighting gradient preventing the definition of a threshold level between both minerals, the mean intercept length is an average of the overall anisotropy without possible distinction between the minerals. Such results are therefore provided with a warning " $100 \% A^{w}$ ".

Multiple edges formed along a scan line tangential to the object boundary (Fig. 2c) are smoothed out (Fig. 2d) with a low-pass filter in grey levels having the same coefficients of Eq. (10). The effective intercept count $N_{1}$ is done by the calculation of the absolute value of a gradient applied to the smoothed scan line:

The precise location of the intercept is at mid-distance of the resulting edge (or gradient) amplitude profile, which is maximum on each intercept spot (Fig. 2h). The level of intercept detection is set by a threshold value. Setting it at 150 would give 1 intercept in Fig. $2 \mathrm{~h}$ while setting it at 50 would gives 2 intercepts. 
Unlike the original intercept method for digital images, a minimum distance between objects is not required in grey levels since objects with sufficient edge amplitudes can be directly in contact with each other. However, any object smaller than half the size of a smooth filter remains invisible.

When a rock sample occupies only a fraction of an image, which is typically the case on a thin section, it is surrounded by a white (in the case of plane light) or black (for polarized light) background which must not be analyzed. Fig. 3a is a test image made of adjacent rectangles with an aspect ratio of 2 , simulating ideal crystals of a sample truncated at various distances from their boundaries, in such a way that the apparent aspect ratio is not preserved on the sample boundary. By masking the pixels of the background, we avoid the analysis of the insignificant sample boundary (Fig. 3b). The efficiency of the intercept method to analyze objects truncated by any window of measurement is also attested by a complementary analysis of the image through four overlapping sub-windows giving identical results. Fig. $3 \mathrm{c}$ displays the Fourier power spectrum and the truncation level of the Fourier series. Individual roses of mean intercept length are shown at the center of their sub-windows of analysis in Fig. 3b, and the main one is presented in Fig. 3d with the final results. Fig. 3e details the area of each overlapping sub-window which scans the image along horizontal and vertical directions. The overlapping is set at 50\% in both directions as defined by Launeau and Robin (2005).

When mean length roses are ellipses on sections, they can be combined with other sections to calculate a 3-dimensional ellipsoid following the procedure defined by (Robin, 2002) and (Launeau and Robin, 2005). The benefit of this new version of intercept counting is in fact its ability to provide a fast analysis of digital images, which can be combined together in the field on a portable computer to provide ellipsoid, lineation (long axis) and foliation (plan perpendicular to the short axis).

\section{Application to theoretical shapes}

A full discussion on the intercept mean length rose can be found in Launeau and Robin (1996). It is sensitive to boundaries. However, a short test on synthetic images is presented here to clarify the distinction between anisotropies of (passive) objects without contrast and (active) objects with infinite contrast of viscosity with their surrounding matrix. These are, respectively, soft objects that are passively deformed in their matrix, and rigid objects that are continuously rotating and interacting with each other in their matrix and preferentially oriented along the flow direction (see also the discussion in Launeau, 2004).

The initial state of the matrix is presented as a disk (Fig. 4a) and four rectangles at 0, 45, 90 and $135^{\circ}$ (Fig. 4c and e) simulating an initial isotropic SPO. A passive simple shear intensity of $4 \gamma$ applied to the disk gives an ellipse (Fig. 4b) and four deformed rectangles (Fig. 4d). The active simple shear applied to four rectangles maintains the individual shapes and only changes their orientations (Fig. 4f). The results may be compared with the expected values presented in Table 1. The preferred orientation of the 4 active rectangles is given by the cosine direction matrix of Harvey and Laxton (1980). The first set of intercept results uses the Launeau and Robin (1996) method while the second set of results (in bold) uses the new grey level count of intercepts.

The intensity of the passive deformations is closer to the expected values. In the first version of intercept counting, the Fourier series was truncated at 24 whereas the truncation level 
increases to 72 with the new version because of better noise filtering as shown in Fig. 2. This high number of power spectrum harmonics is necessary to analyze angular objects like rectangles, which display a long rectilinear boundary particularly sensitive to noise when the scan lines are tangential to it.

\section{Application to the BSE image of a synthetic magma}

To investigate the role of structures, such as mineral fabrics and mechanical anisotropies, in the flow mechanism of crystallizing magmas, a plagioclase-bearing suspension composed of $52 \%$ of crystals was synthesized and then deformed using a Paterson HP-HT apparatus at a confining pressure of $300 \mathrm{MPa}$, a temperature of $850^{\circ} \mathrm{C}$, a shear strain rate $\gamma=3.10^{-4} \mathrm{~s}^{-1}$ and a shear strain $\gamma=3.5$. A thin section, normal to the radius of the core ([X Z] section), was prepared in the deformed sample. In this section, the applied deformation approximates simple shear. Deformation textures were observed with a scanning electron microscope (SEM) on back scattered electron (BSE) images. Plagioclase shape fabrics were determined by using the grey level intercept method with $16 \times 16$ sub-windows (Fig. 5) individually overlapping their neighbors by $50 \%$.

The intercept method reveals a strong SPO of the fabric developed with an average orientation $\alpha=49.73^{\circ}$ anticlockwise with respect to the shear direction (SD). This mineral foliation is locally crosscut by a $40 \mu \mathrm{m}$ thick shear zone oriented at $8^{\circ}$ clockwise from the SD and bordered by shear gradients indicating normal shear direction. The SPO of the fabric inside the shear zone is oriented in the shear direction. The obtained microstructures are consistent with those observed in natural magmatic rocks ([Nicolas, 1992], [Ildefonse et al., 1992a], [Ildefonse et al., 1992b] and [Smith, 2002]) and confirm that the results obtained in experiments can be extended to natural conditions. The segmentation of all aggregated crystals by hand is time-consuming. It has been shown that the intercept method in grey levels may find all the critical parameters, including the local shear zone, without tedious image processing.

\section{Application to quartz-rich rocks}

The use of the intercept technique in grey level images is illustrated in a weakly deformed quartzite (see page 118 of Ramsay and Huber, 1983) and an undeformed quartz arenite from the Upper Paleozoic glacial deposits of the Paraná Basin (Southern Brazil).

The quartzite was selected to compare counting intercepts in the grey level given by the orientation of the quartz-c axis and intercepts on grain boundaries drawn manually (Fig. 6). Both images, the thin section and its drawing, were scanned at $300 \mathrm{dpi}$. The SPOs are quite similar to each other. The main difference is in their size. The extinction of certain grains of quartz makes a part of their boundary invisible. The division of the surface area by a smaller number of boundaries yields bigger intercept lengths. However, the shape ratio and the orientation remain the same in both the drawing and the thin section picture.

The sample of sandstone in Fig. 7 comes from alluvial-coastal arenite and conglomerate deposits with a paleoslope to the west. An oriented sample was collected in a quartz-arenite bed just below striated pavements formed by glacial erosion (Witmarsun village, Paraná State). The striae indicate that the ice moved to the northwest, while paleocurrents in tabular clastic deposits with abundant cross-bedding indicate flows mostly to the west (Assine, 1999). The sandstone specimen was cut in three mutually orthogonal thin sections, one of them 
approximately parallel to a crude subhorizontal bedding visible at the sampling site (XY plane in Fig. 7). The use of the rotating polarizer stage of Fueten and Goodchild (2001) avoids periodic extinctions and thus preserves most of the boundaries. Quartz grains are angular to sub-angular in shape and poorly sorted with some grains reaching $2 \mathrm{~mm}$ in length. The grain SPO on each thin section was analyzed with $9 \times 9$ overlapping sub-windows, which, with a combination of 3 sections and nine sub-windows, yielded 729 ellipsoids. The fit of the ellipsoids to the ellipsoid sought is given by the parameter, which is ideal when $\quad=0 \%$ and poorly defined above, say, 10\% (Launeau and Robin, 2005). The low value of the fit parameter $(2.3 \%)$ indicates that the sampled area in each sub-window is homogeneous. It shows that the quartz fabric defines a shape foliation dipping to the west and a lineation that tends to scatter, consistent with the moderately oblate shaped ellipsoid $(T=0.34)$. Hence, the calculated grain fabric probably records the cross-bedding of sandwaves produced by down current migration towards the basin paleoslope.

\section{Application to a granite}

The granite quarry near Pocinhos (Paraíba State, NE Brazil) is part of the Archanjo and Fetter (2004) study (station \#128). Field pictures were taken with a digital camera in the quarry at two sites $50 \mathrm{~m}$ apart from each other. Each image was analyzed with $9 \times 9$ overlapping subwindows to check the homogeneity of the data by combining them into 729 ellipsoids, as shown in Fig. 8. All the classical parameters presented in this figure show that the intercept method is repeatable at the scale of a quarry and that such low SPO are quite stable in orientation and intensity. We consider that the continuity of the data from site to site is the best test to check their validity. We also stress that the three sections do not have to be parallel or perpendicular to foliation and lineation. The freedom to use any set of three or four sections with a wide angle between them, with no prior knowledge of the structure, facilitates the collection of data and reinforces the objectivity of the method. This method just needs clean, nearly flat and large enough rock sections with a good contrast between minerals.

\section{Conclusion}

A long (10 pixels) linear low-pass filter along scan lines coupled with a short gradient detector allowed us to count intercepts with grey levels with a minimum of image preprocessing. By combining this technique with the ellipsoid calculation described by Robin (2002), we were able to determine the grain fabric from images taken in field studies with a digital camera, as well as from petrographic thin sections of hand specimens. The fabric recorded by the intercept method in grey levels is an average of the orientation distribution of the boundaries of a mineral phase that shows sufficient contrast with its matrix. Complex distributions of crystals deformed in a Paterson HP-HT apparatus can be detected by subdividing a BSE image into sub-windows and analyzing the respective sub-fabrics. For geological applications, the method provided useful results: (i) in a coarse-grained granite quarry with clean, sufficiently large and planar rock sections, and (ii) on petrographic thin sections of quartz-rich rocks, in which grey level variations depended on the position of the crystallographic axes. However, the simplicity of the method should not hide the fact that an operator must make a few hypotheses about the mechanisms involved in the formation of SPO and analyze the results in the geological context of the sample.

Site to download the program: http://www.sciences.univ-nantes.fr/geol/SPO/. 


\section{Acknowledgements}

P. Launeau thanks the University of São Paulo and FAPESP (grants 01/14154-2 and 04/13121-1) for fruitful scientific collaboration while the author was a guest of the Instituto de Geociências of São Paulo in 2003 and 2005.

C. Archanjo also thanks FAPESP (grant 01/10626-7) and the Faculté des Sciences et des Techniques of Nantes for his invitation as a professor at the University of Nantes in 2001 and 2005, and Jacques Girardeau for making his research in Nantes possible.

D.P. and L.A. was funded by the French Program ANR-EXPLANT (Contract No ANR-05CATT-003 to C. Martel).

We all thanks Frank Fueten and anonymous reviewer for their fruitful comments.

\section{References}

Archanjo and Fetter, 2004 C.J. Archanjo and A.H. Fetter, Emplacement setting of the granite sheeted pluton of Esperaça (Brasiliano orogen, northeastern Brazil), Precambrian Research 135 (2004), pp. 193-215.

Archanjo et al., 2009 C.J. Archanjo, P. Launeau, M.H.B.M. Hollanda and D. Liu, Scattering of magnetic fabrics in the Cambrian alkaline granite of Meruoca (Ceará State, northeastern Brazil), International Journal of Earth Sciences 8 (2009), pp. 1437-3254.

Assine, 1999 M.L. Assine, Facies, icnofósseis, paleocorrentes e sistemas deposicionais da Formação Furnas no flanco sudeste da Bacia do Paraná, Revista Brasileira de Geociencias 29 (1999), pp. 357-370.

Coster and Chermant, 1989 M. Coster and J.L. Chermant, Précis d'analyse d'images, Presses du C.N.R.S, Paris (1989) 560 pp..

Diot et al., 2003 H. Diot, O. Bolle, J.-M. Lambert, P. Launeau and J.-C. Duchesne, The Tellnes ilmenite deposit (Rogaland, South Norway): magnetic and petrofabric evidence for emplacement of a Ti-enriched noritic crystal mush in a fracture zone, Journal of Structural Geology 25 (2003), pp. 481-501

Fueten and Goodchild, 2001 F. Fueten and J.S. Goodchild, Quartz c-axes orientation determination using the rotating polarizer microscope, Journal of Structural Geology 23 (2001), pp. 895-902.

Gaillot et al., 1999 P. Gaillot, J. Darrozes and J.-L. Bouchez, Wavelet transform: a future of rock fabric analysis?, Journal of Structural Geology 21 (1999), pp. 1615-1621.

Harvey and Laxton, 1980 P.K. Harvey and R.R. Laxton, The estimate of finite strain from the orientation distribution of passively deformed linear markers: eigenvalue relationships, Tectonophysics 70 (1980), pp. 285-387. 
Ildefonse et al., 1992a B. Ildefonse, P. Launeau, A. Fernandez and J.L. Bouchez, Effect of mechanical interactions on development of shape preferred orientations: a two-dimensional experimental approach, Journal of Structural Geology 14 (1) (1992), pp. 73-83.

Ildefonse et al., 1992b B. Ildefonse, D. Sokoutis and N.S. Mancktelow, Mechanical interactions between rigid particles in a deforming ductile matrix: analogue experiments in simple shear flow, Journal of Structural Geology 14 (10) (1992), pp. 1253-1266.

Jelinek, $1981 \mathrm{~V}$. Jelinek, Characterization of the magmatic fabrics of rocks, Tectonophysics 79 (1981), pp. 63-67.

Launeau, 2004 P. Launeau, Mise en évidence des écoulements magmatiques par analyse d'images 2-D des distributions 3-D d'Orientations Préférentielles de Formes, Bulletin. Société Géologique de France 175 (2004), pp. 331-350

Launeau and Robin, 1996 P. Launeau and P.-Y.F. Robin, Fabric analysis using the intercept method, Tectonophysics 267 (1996), pp. 91-119.

Launeau and Robin, 2005 P. Launeau and P.-Y.F. Robin, Determination of fabric and strain ellipsoids from measured sectional ellipses-implementation and applications, Journal of Structural Geology 27 (2005), pp. 2223-2233.

Launeau et al., 1990 P. Launeau, J.L. Bouchez and B. Keith, Shape preferred orientation of object population: automatic analysis of digitized images, Tectonophysics 180 (1990), pp. 201-211.

Lebichot et al., 2005 S. Lebichot, G. Dislaire, E. Pirard and P. Launeau, Grey level intercepts distributions and grain size estimation, Proc. 8th Int. Congr. on Stereol. and Image Anal, Zakopane, PL (2005), pp. 102-110.

Nicolas, 1992 A. Nicolas, Kinematics in magmatic rocks with special reference to gabbros, Journal of Petrology 33 (1992), pp. 891-915.

Panozzo, 1983 R. Panozzo, Two-dimensional analysis of shape fabric using projections of lines in a plane, Tectonophysics 95 (1983), pp. 279-294.

Panozzo, 1984 R. Panozzo, Two-dimensional strain from the orientation of lines in a plane, Journal of Structural Geology 6 (1984), pp. 215-221.

Panozzo, 1987 R. Panozzo, Two-dimensional strain determination by the inverse SURFOR wheel, Journal of Structural Geology 9 (1987), pp. 115-119.

Panozzo Heilbronner, 1988 R. Panozzo Heilbronner, Distortion of orientation data introduced by digitizing procedures, Journal of Microscopy 149 (1988), pp. 83-96.

Panozzo Heilbronner, 1992 R. Panozzo Heilbronner, The autocorrelation function: an image processing tool for fabric analysis, Tectonophysics 212 (1992), pp. 351-370. 
Pirard et al., 2007 E. Pirard, S. Lebichot and W. Krier, Particle texture analysis using polarized light imaging and grey level intercepts, International Journal of Mineral Processing 84 (2007), pp. 299-309.

Ramsay and Huber, 1983 J.G. Ramsay and M.I. Huber, The techniques of modern structural geology, Strain Analysis vol. 1, Academic Press (1983), p. 307.

Robin, 2002 P.-Y.F. Robin, Determination of fabric and strain ellipsoids from measured sectional ellipses — theory, Journal of Structural Geology 24 (2002), pp. 531-544.

Romeo et al., 2007 I. Romeo, R. Capote, R. Lunar and N. Cayzer, Polymineralic orientation analysis of magmatic rocks using Electron Back-Scatter Diffraction: implications for igneous fabric origin and evolution, Tectonophysics 444 (2007), pp. 45-622.

Saltykov, 1958 S.A. Saltykov, Stereometric Metallography (second ed.), Metallurgizdat, Moscow (1958).

Serra, 1982 J. Serra, Image Analysis and Mathematical Morphology, Academic Press (1982).

Smith, 2002 J.V. Smith, Structural analysis of flow-related textures in lavas, Earth Science Review 57 (2002), pp. 279-297.

Underwood, 1970 E.E. Underwood, Quantitative Stereology, Addison-Wesley Publishing Company, Menlo Park, California - London - Don Mils, Ontario (1970), p. 274. 


\section{Figures and Tables}

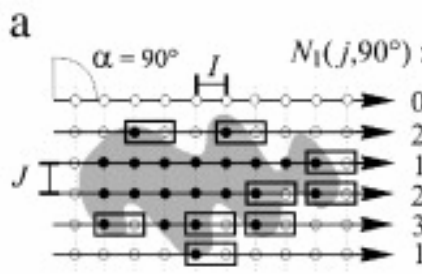

b

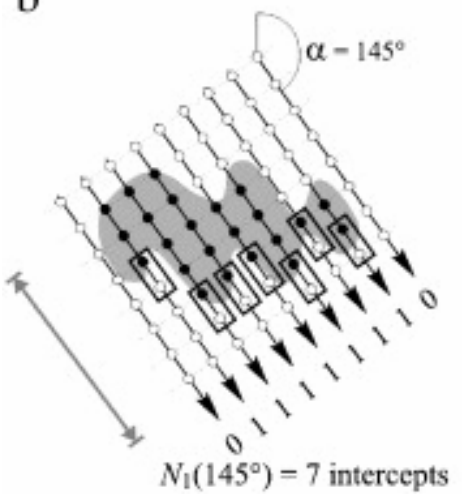

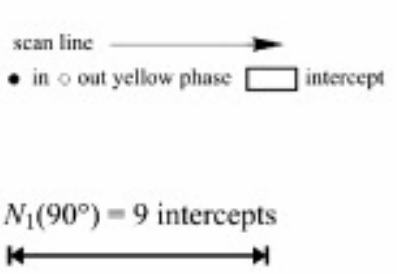

$\mathrm{c}$

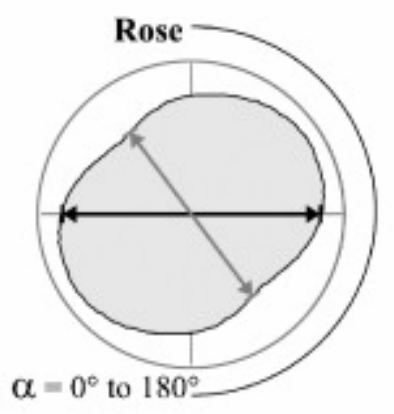

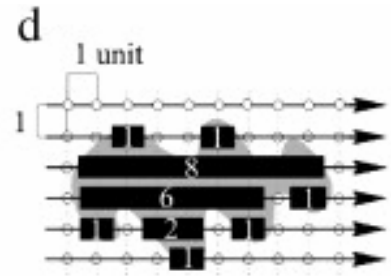

mean length

22 units $/ 9$ segments $=2.4$ units per segment

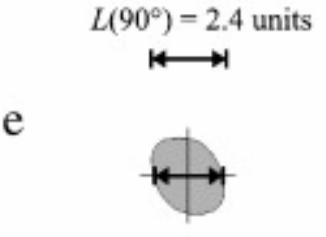

mean length Rose

Fig. 1. Counting grid at a) $\alpha=90^{\circ}$ and b) $\alpha=145^{\circ}$ on a grey shaded object of a phase $X$. Analysis points are represented by open when they fall outside the object, and filled dots when they fall in it. The number of intercepts $N_{1}$ on a line $j, N_{1}(j, \alpha)$, is the number of times, in boxes, a cursor migrating along that line moves out of phase $X$. For several equally-spaced lines parallel to a direction $\alpha$, the total number of intercepts is $N_{1}(\alpha)$. c) Rose of intercept counts, $N_{1}(\alpha)$, plot from 0 and $360^{\circ}$. d) The number of analysis points falling into a phase $X$ divided by the number of intercepts along a line $j, N_{1}(j, \alpha)$, gives the mean intercept length

. e) Rose of mean intercept length $\underline{\underline{L}}(\boldsymbol{\alpha})$ 

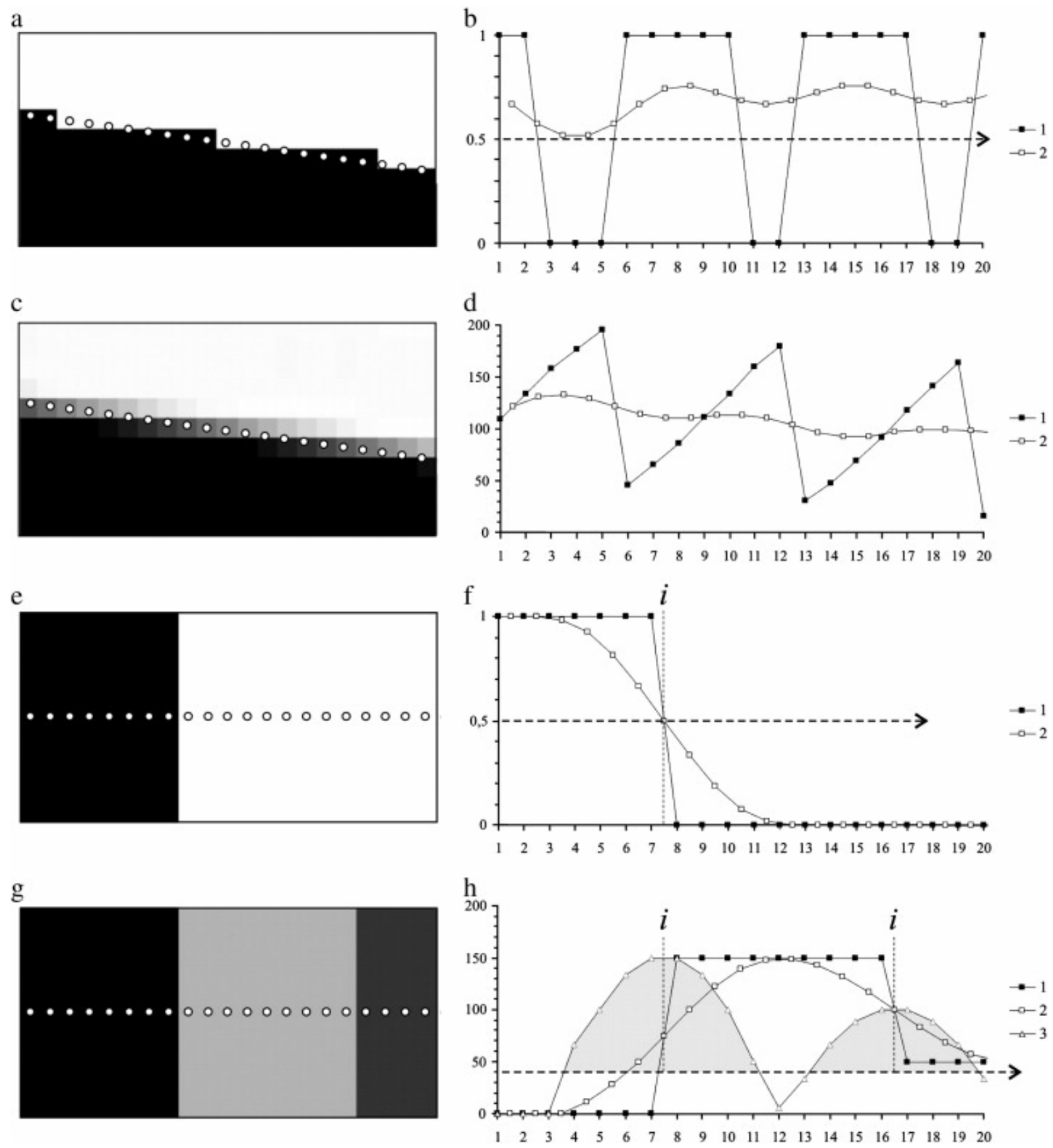

Fig. 2. a) Binary image of a mineral phase $X$ in black and its matrix in white; dots are points of analysis. b) 1 - raw profile of point sampling ( 1 is in and 0 is out of the mineral phase); 2 - profile of local density of samples belonging to the phase $X$ weighted by $[1,3,6,8,9,9,8$, $6,3,1] / 54$. c) Grey level image of a black mineral phase and its white matrix with dots indicating points of analysis. d) - 1 raw profile of sample in grey levels; -2 smoothed profile with the grey level filter $[1,3,6,8,9,9,8,6,3,1] / 54$. e) Binary image with perpendicular line of analysis. f) 1 - raw profile of point sampling; 2 - profile of local density with detection of intercept $i$. g) Same image as (e) in grey levels prior to a thresholding splitting it into binary values. h) 1 - raw profile of point sampling; 2 - profile smoothed by a low-pass filter $([1,3,6,8,9,9,8,6,3,1] / 54) ; 3$ - absolute value of the $[-1$ $1] \times 6$ gradient of line 2 giving a profile of edge amplitude with detection of intercept $i$ at an amplitude greater than 40 . Each intercept is located at the mid-distance of edge amplitude greater than a threshold value set at 40 in this example. 
a

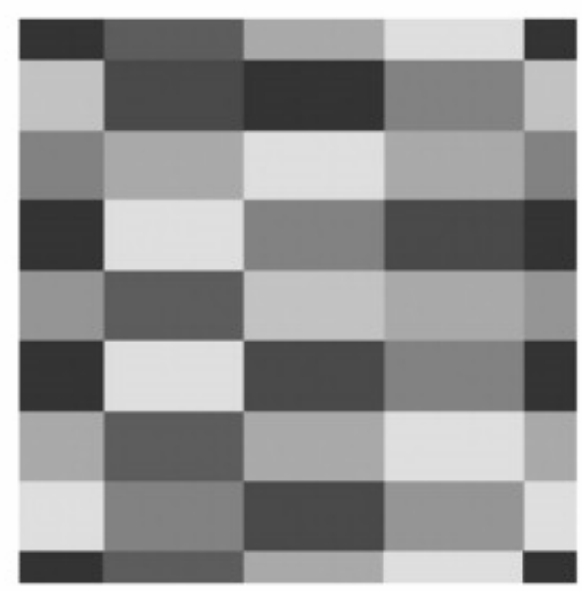

b

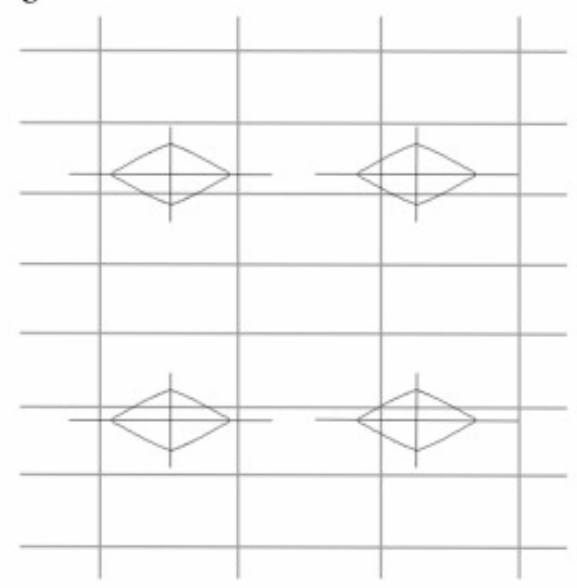

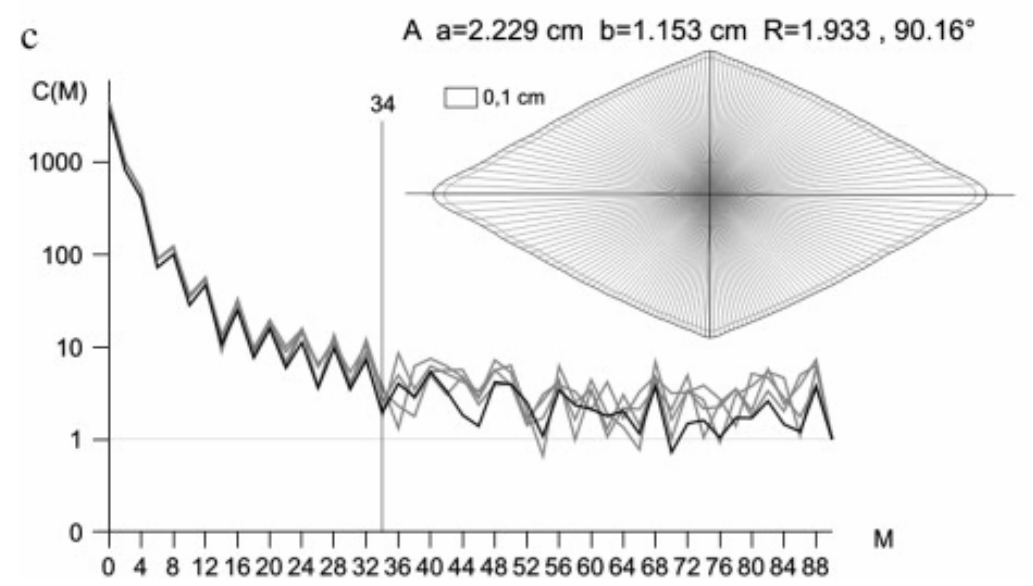

d
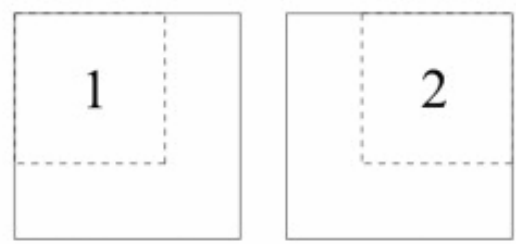

$\mathrm{e}$
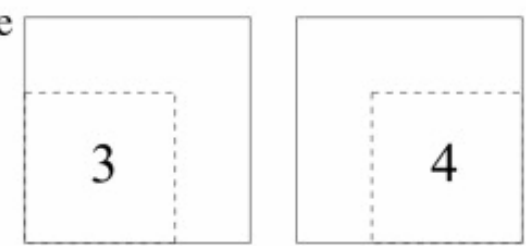

Fig. 3. Sensitivity of the intercept method to the window of measurement boundary. a) Set of rectangles simulating a sample of rock with a large white empty space on the border. b) Location of intercepts counted on the image and the mean length intercept rose diagram at the center of each sub-window of measurement. c) Fourier power spectrum of an intercept count truncated at 24 for the inverse Fourier transform and d) Fourier rose diagram of mean length intercepts with final results. Note that rectangles necessitate a thin angular step of analysis $\left(2^{\circ}\right)$ to analyze their corners fully. e) Scheme of the sub-window scan set-up with $50 \%$ overlapping in line and column directions. 


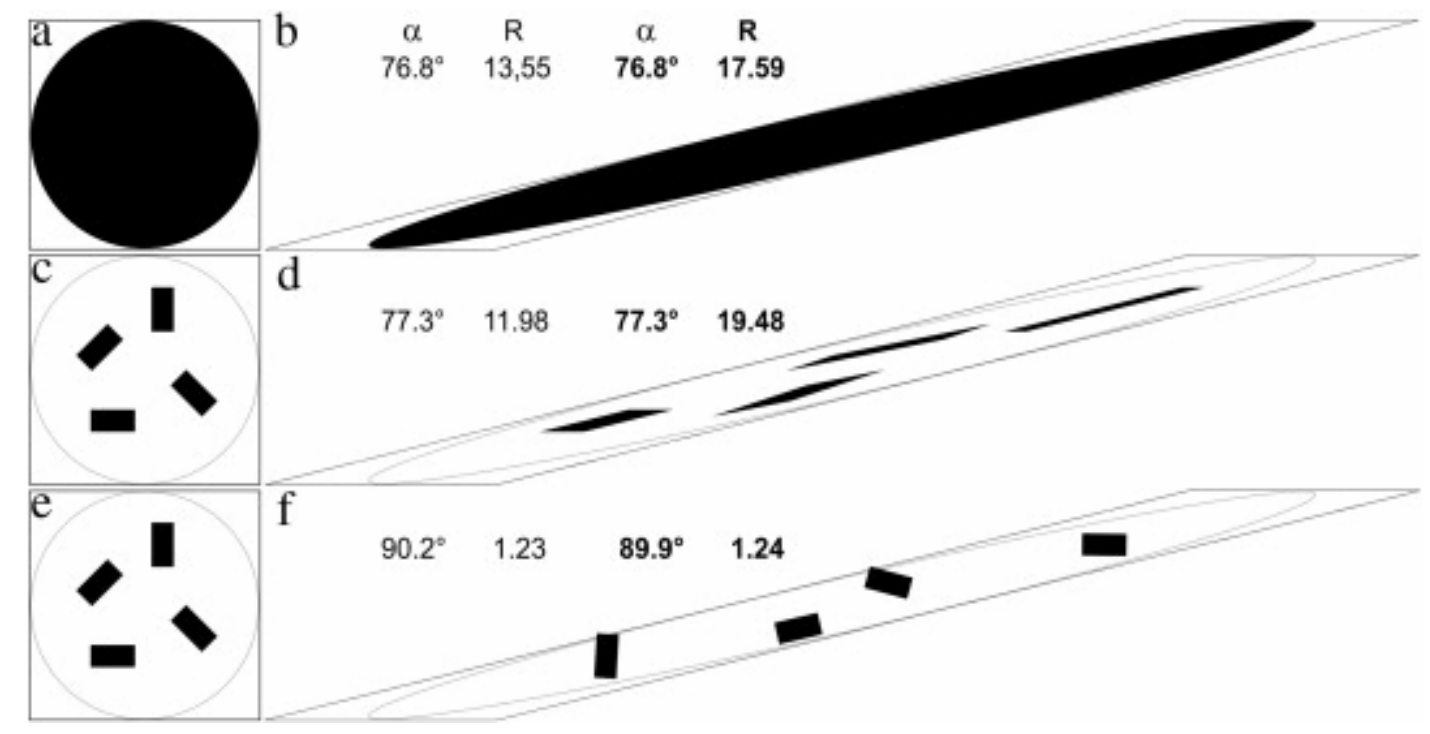

Fig. 4. a) Enclave passively deformed in (b). c) Set of soft rectangles passively deformed in (d). e) Set of rigid rectangles embedded in a matrix deformed in (f).

Table 1. The expected values for passive and active deformations at $4 \gamma$ of the synthetic objects presented in Fig. 4.

\begin{tabular}{|l|l|l|l|l|l|}
\hline \multicolumn{3}{|l|}{ Passive } & \multicolumn{3}{l|}{ Active } \\
\hline$\gamma$ & $\varphi$ & $\mathrm{R}$ & $\gamma$ & $\gamma \mathrm{c}$ & $\mathrm{Rmax}$ \\
\hline 4 & 76.0 & 17.94 & 4 & 3.927 & 2 \\
\hline & $\varphi$ & $\mathrm{R}$ & & $\varphi$ & $\mathrm{R}$ \\
\hline 4 rect. & 77.4 & 17.94 & 4 rect. & 90.6 & 1.609 \\
\hline
\end{tabular}



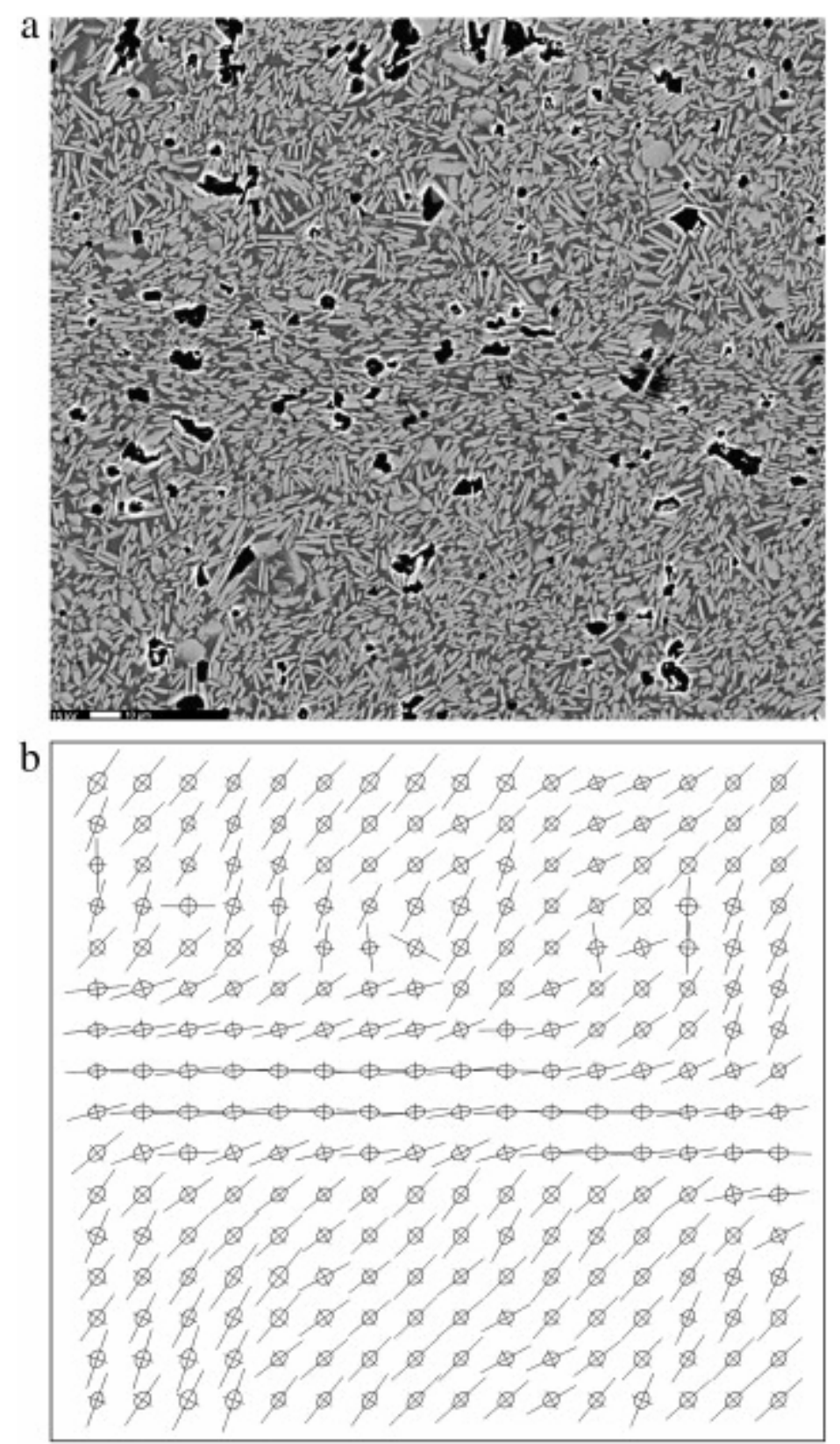

Fig. 5. a) Back scattered electron SEM image of a synthetic lava deformed at $3 \mathrm{kbar}, 850{ }^{\circ} \mathrm{C}$, gamma $=3.5$, gamma dot $=3.10-4 \mathrm{~s}^{-1}$ (crystals are in light grey, the melt in dark grey and bubbles in black), b) $16 \times 16$ mean intercept length roses (not scaled to the image) revealing a shear zone in the middle of the sample. 

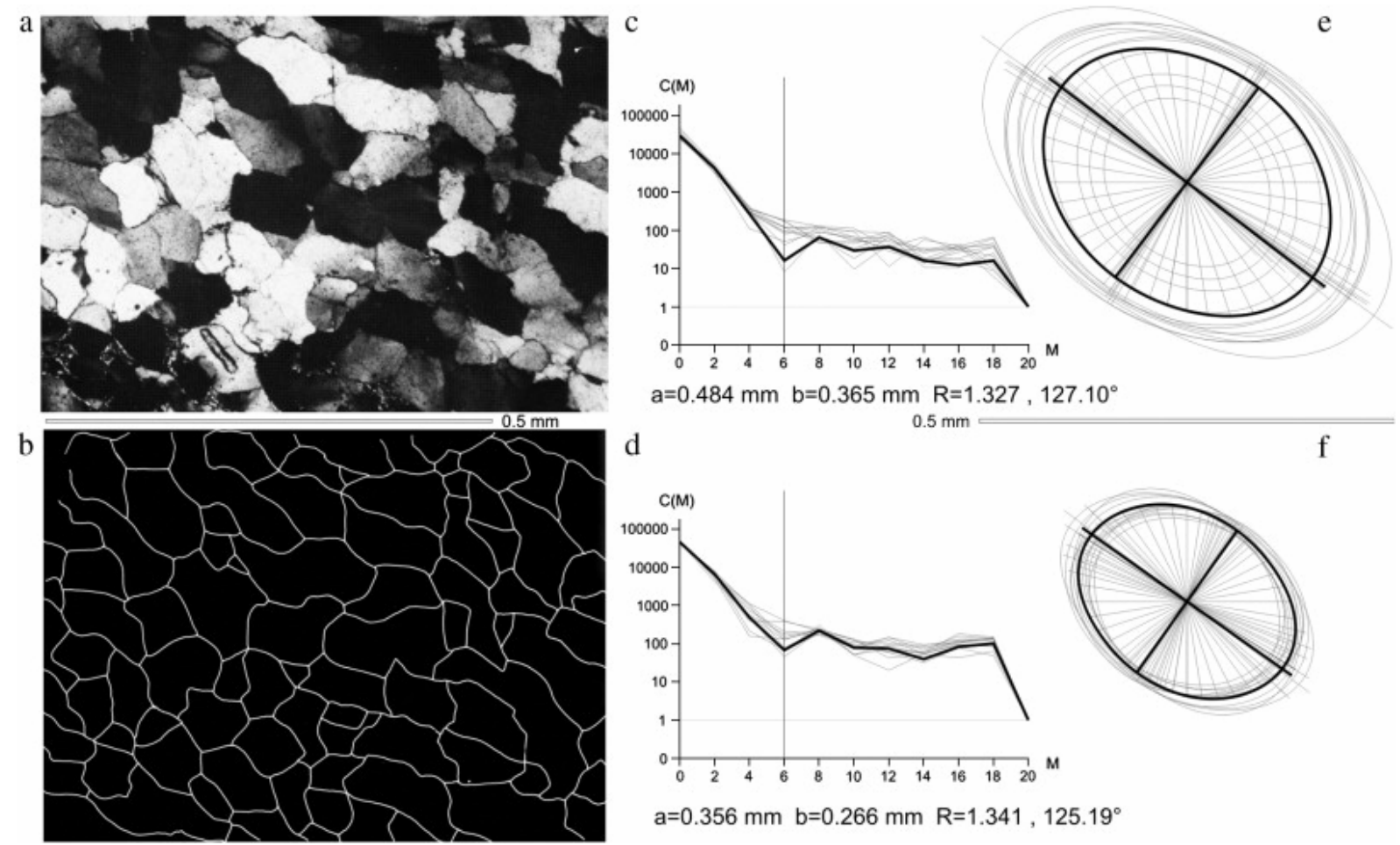

Fig. 6. Applications to a picture and a drawing of a quartzite thin section from Ramsay and Huber (1983, page 118). a) 300 dpi of the thin section picture, b) its corresponding drawing. c) and d) are their corresponding Fourier power spectra with level of truncation to plot final mean length intercept roses in e) and f) respectively. Both sets of roses are scaled to each other. Data collected in sub-windows are in grey and means are in black. 

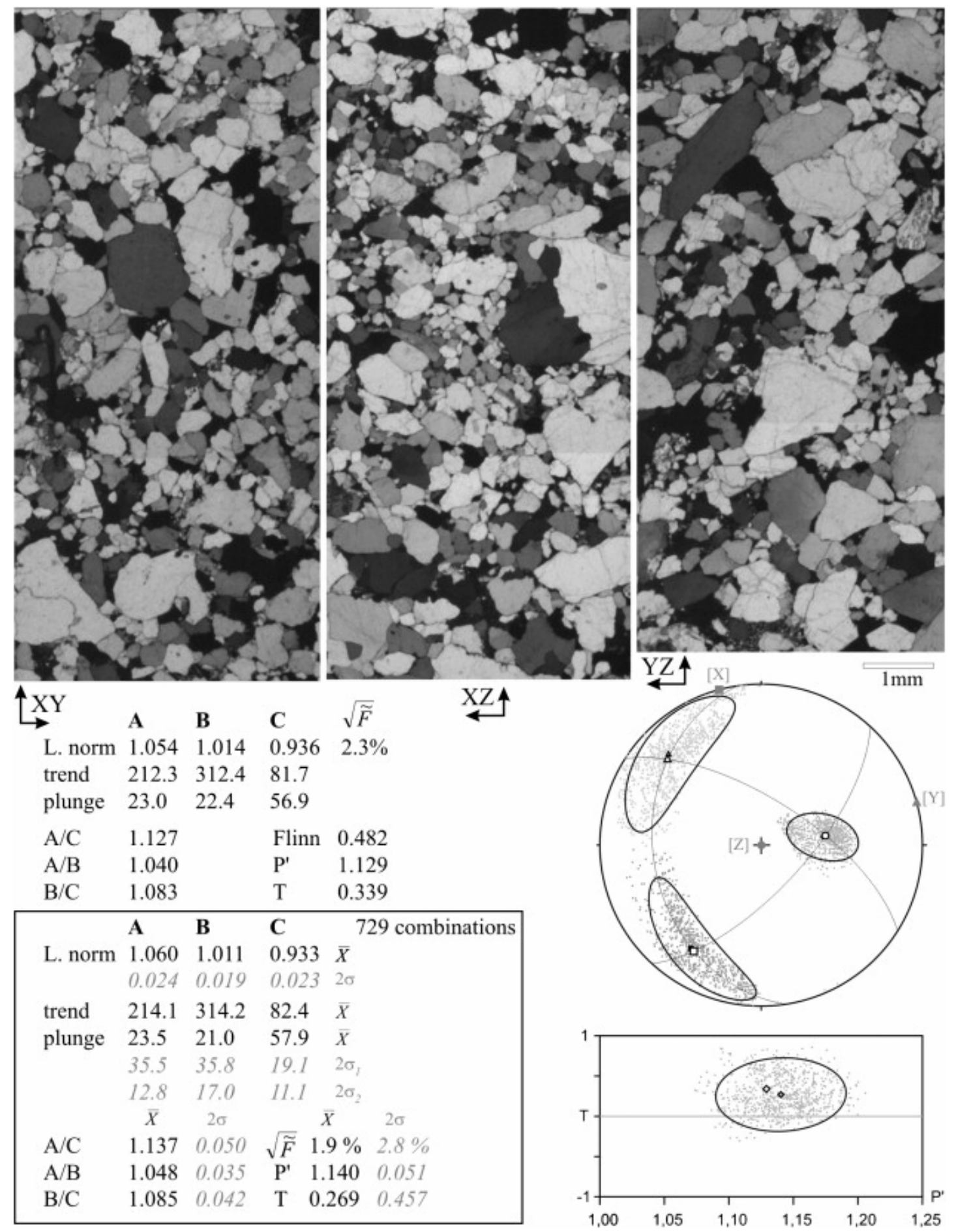

Fig. 7. Application to maximum polarized light, using Fueten and Goodchild (2001) methodology; thin sections of sandstones from the Devonian beds of the Furnas Formation (Brazil); see text for discussion. Jelinek (1981) parameters are $P^{\prime}=\exp \left[2\left(l_{1}^{2}+l_{2}^{2}+l_{3}^{2}\right)\right]^{1 / 2}$, $T=\left[2\left(\ln b_{2}-\ln b_{3}\right) /\left(\ln b_{1}-\ln b_{3}\right)\right]-1$ with $l_{n}=\ln \left(b_{n} / b_{B}\right)$ and $b_{B}=\left(b_{1} \cdot b_{2} \cdot b_{3}\right) / 3$.

is discussed in Robin (2002). Stereograms are lower hemispheres of equal area projections showing that sections of measurement [1] for YZ, [2] for XZ and [3] for XY are oblique on the characteristic planes of the SPO ellipsoid whose principal axes are labeled A, B and C. Images are mosaics of 3 maximum polarized light digital pictures. 

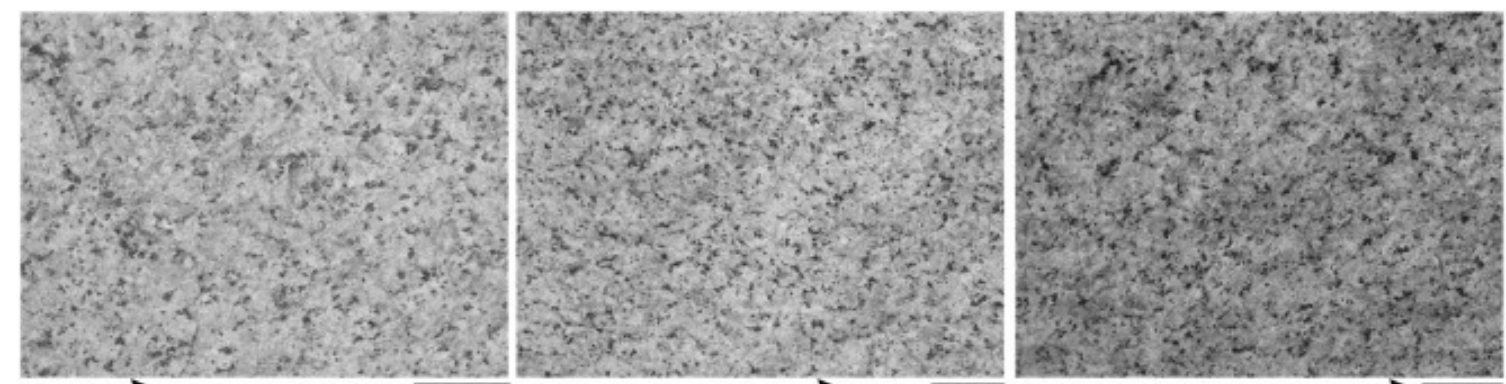

\begin{tabular}{|c|c|c|c|c|c|}
\hline \multicolumn{2}{|l|}{$1.1 \overrightarrow{217 / 11}$} & \multicolumn{3}{|c|}{$10 \mathrm{~cm}$} & 1.2 \\
\hline & $\mathbf{A}$ & B & C & $\sqrt{\tilde{H}}$ & \\
\hline L. norm & 1.095 & 0.996 & 0.916 & 1.4 & $4 \%$ \\
\hline trend & 177.6 & 75.9 & 311.9 & & \\
\hline plunge & 26.8 & 22.0 & 54.2 & & \\
\hline $\mathrm{A} / \mathrm{C}$ & 1.196 & & Flinn & 1.1 & 25 \\
\hline $\mathrm{A} / \mathrm{B}$ & 1.099 & & $\mathrm{P}^{\prime}$ & 1.1 & 196 \\
\hline $\mathrm{B} / \mathrm{C}$ & 1.088 & & $\mathrm{~T}$ & & 059 \\
\hline & $\mathbf{A}$ & B & $\mathbf{C}$ & & 729 combinations \\
\hline L. norm & 1.098 & 0.995 & 0.916 & $\bar{x}$ & \\
\hline & 0.030 & 0.015 & 0.023 & $32 \sigma$ & \\
\hline trend & 177.5 & 75.9 & 311.9 & $\bar{x}$ & \\
\hline plunge & 26.6 & 22.0 & 54.2 & $\bar{X}$ & \\
\hline & 13.1 & 13.4 & 7.1 & $2 \sigma_{l}$ & \\
\hline & 3.8 & 6.5 & 3.7 & $2 \sigma_{2}$ & \\
\hline & $\bar{X}$ & $2 \sigma$ & & $\bar{X}$ & $2 \sigma$ \\
\hline $\mathrm{A} / \mathrm{C}$ & 1.199 & 0.061 & $\sqrt{\widetilde{F}} 1$ & $1.7 \%$ & $1.8 \%$ \\
\hline $\mathrm{A} / \mathrm{B}$ & 1.103 & 0.040 & $\mathrm{P}^{\prime} \quad 1$ & 1.201 & 0.061 \\
\hline $\mathrm{B} / \mathrm{C}$ & 1.087 & 0.035 & $\mathrm{~T}-$ & -0.076 & 60.255 \\
\hline
\end{tabular}
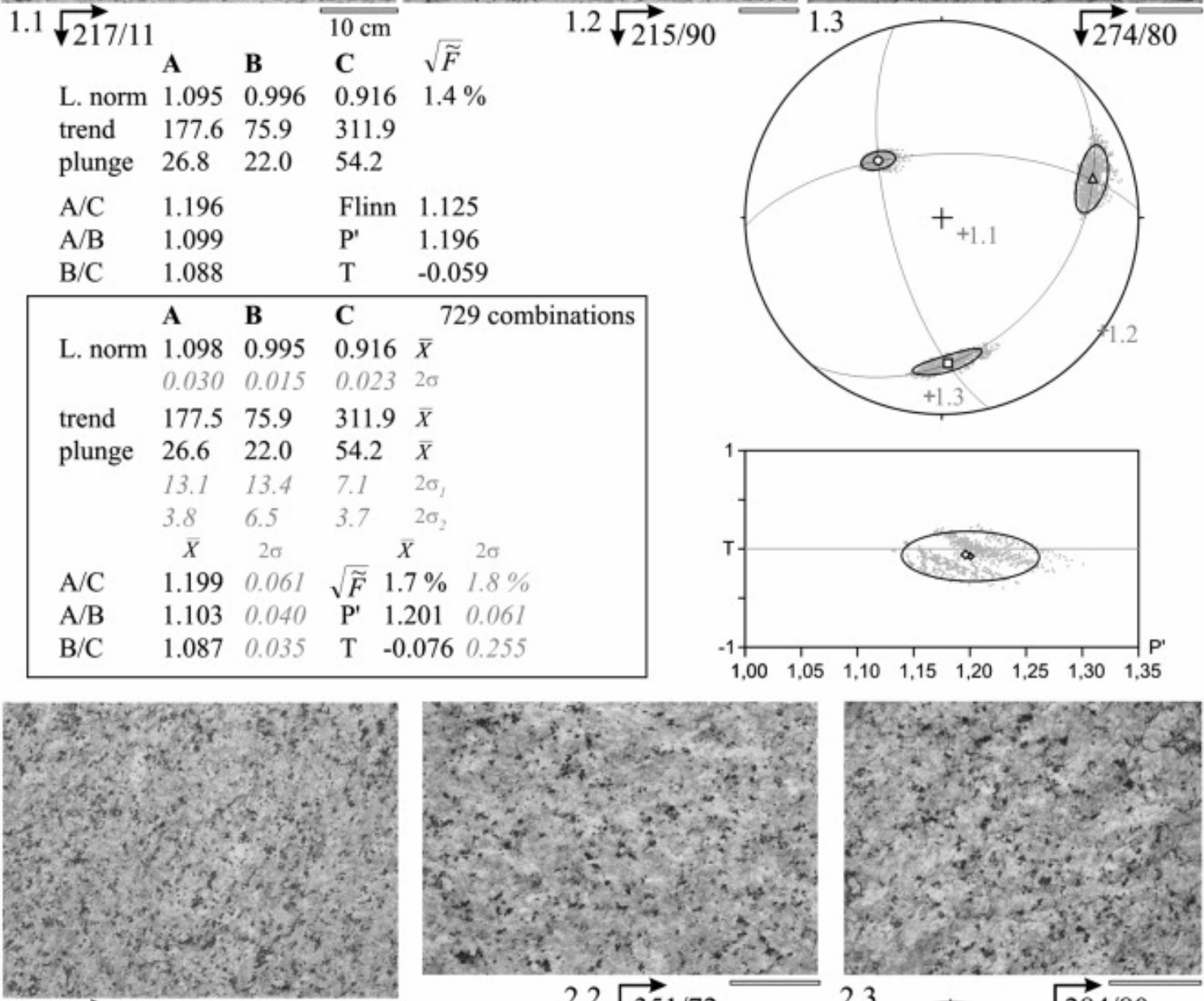

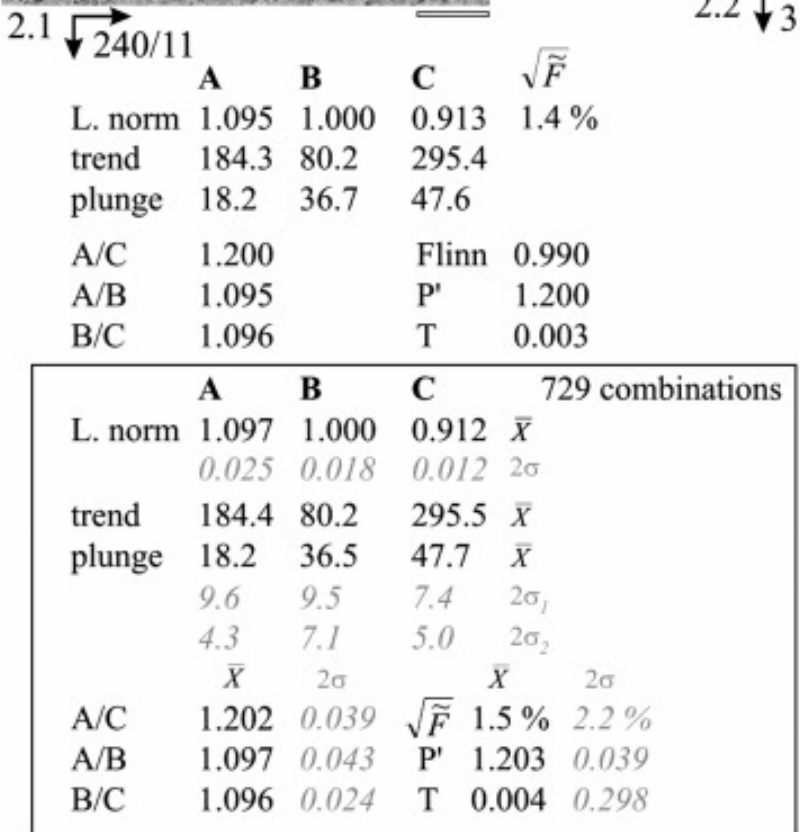
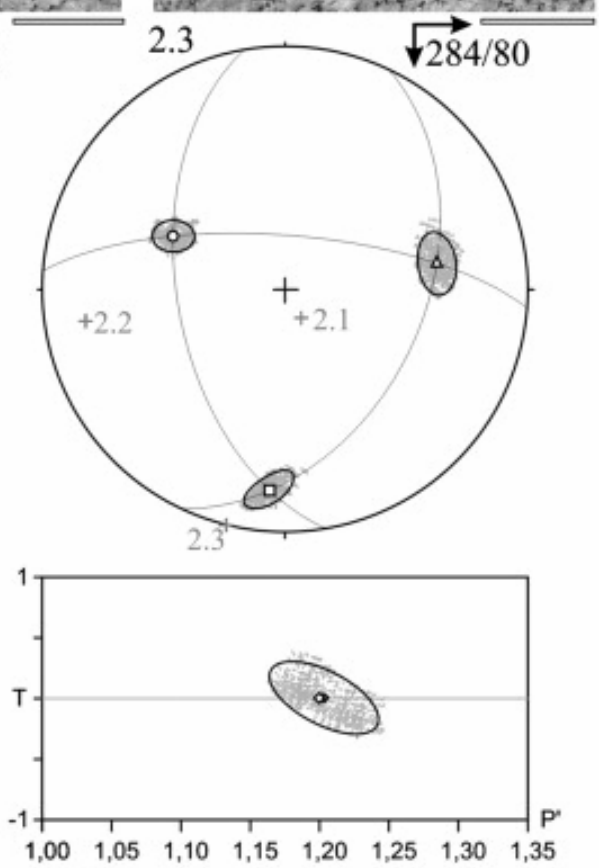
Fig. 8. Application to two sites of Pocinhos granite (Paraíba State, NE Brazil). A set of 3 nearly perpendicular digital pictures (\# 1.2 to 1.3 on site 1 and \# 2.1 to 2.3 on site 2) are oriented in the field and analyzed with the grey level intercept method applied to $9 \times 9 \mathrm{sub}-$ windows leading to 729 combinations of ellipsoids using the Robin (2002) method. Despite particularly weak fabrics, both sites give similar results. Stereograms are lower hemispheres of equal area projections. Fabric parameters are defined in Fig. 7. Mean intercept lengths are typically equal to mean intercept distances in this case. This is not important since we are only concerned by relative or normalized lengths. 